\title{
Efficacy and safety of autologous adipose-derived stromal vascular fraction enriched with platelet-rich plasma in flap repair of transsphincteric cryptoglandular fistulas
}

\author{
W. R. Schouten ${ }^{1}$ - J. H. C. Arkenbosch ${ }^{2}$ (I) . C. J. van der Woude ${ }^{2}$ - A. C. de Vries ${ }^{2}$ • H. P. Stevens ${ }^{3}$ - G. M. Fuhler ${ }^{2}$. \\ R. S. Dwarkasing ${ }^{4}$ O. van Ruler $^{1,2} \cdot$ E. J. R. de Graaf ${ }^{1}$
}

Received: 14 May 2021 / Accepted: 7 September 2021 / Published online: 4 October 2021

(c) The Author(s) 2021

\begin{abstract}
Background Transanal advancement flap repair of transsphincteric fistulas is a sphincter-preserving procedure, which frequently fails, probably due to ongoing inflammation in the remaining fistula tract. Adipose-derived stromal vascular fraction (SVF) has immunomodulatory properties promoting wound healing and suppressing inflammation. Platelet-rich plasma (PRP) reinforces this biological effect. The aim of this study was to evaluate the efficacy and safety of autologous adipose-derived SVF enriched with PRP in flap repair of transsphincteric cryptoglandular fistulas.

Methods A prospective cohort study was conducted including consecutive patients with transsphincteric cryptoglandular fistula in a tertiary referral center. During flap repair, SVF was obtained by lipoharvesting and mechanical fractionation of adipose tissue and combined with PRP was injected around the internal opening and into the fistulous wall. Endpoints were fistula healing at clinical examination and fistula closure on postoperative magnetic resonance imaging (MRI). Adverse events were documented.

Results Forty-five patients with transsphincteric cryptoglandular fistula were included ( 29 males, median age 44 years [range 36-53 years]). In the total study population, primary fistula healing was observed in 38 patients (84\%). Among the 42 patients with intestinal continuity at time of surgery, primary fistula healing was observed in 35 patients (84\%). In one patient, the fistula recurred, resulting in a long-term healing rate of $82 \%$. MRI, performed in 37 patients, revealed complete closure of the fistula tract in $33(89.2 \%)$. In the other patients, the tract was almost completely obliterated by scar tissue. During
\end{abstract}

Abstract published in Journal of Crohn's and Colitis Volume 13, Issue Supplement 1, March 2019, Pages S315-S316.

Oral presentation at International Digestive Disease Forum 2019

Hong Kong, runner-up IDDF Young Investigator Award.

Oral presentation at Dutch Digestive Disease Days, Veldhoven, The Netherlands, March 2019.

Oral presentation at Dutch Surgeon Days, Veldhoven The Netherlands, May 2019.

Poster presentation at European Crohn's and Colitis Organization Congress March 2019.

Video publication in DCR: Deijl W, Arkenbosch J, van Ruler O, van der Woude CJ, Stevens HPJD, de Graaf E, Schouten R. Autologous Platelet-Rich Stroma in Complex Perianal Fistulas. Dis Colon Rectum. 2020 Jun 63(6):860-861. PMID: 32384409.

W. R. Schouten and J. H. C. Arkenbosch share first authorship.

Extended author information available on the last page of the article 
follow-up, none of these patients showed clinical signs of recurrence. The postoperative course was uneventful, except for three cases; venous thromboembolism in one patient and bleeding under the flap, necessitating intervention in two patients. Conclusions Addition of autologous SVF enriched with PRP during flap repair is feasible, safe and might improve outcomes in patients with a transsphincteric cryptoglandular fistula.

Trial registration Dutch Trial Register, Trial Number: NL8416, https://www.trialregister.nl/

Keywords Perianal fistula $\cdot$ Surgery $\cdot$ Cryptoglandular $\cdot$ Stromal vascular fraction $\cdot$ Platelet-rich stroma $\cdot$ Platelet-rich plasma

\section{Introduction}

Transanal advancement flap repair (TAFR) is one of the most important sphincter-preserving procedures for the treatment of transsphincteric cryptoglandular fistulas. Despite many attempts to improve outcome, this procedure still fails in about $40 \%$ of tertiary referral patients with complex fistula [1]. This high failure rate is probably due to ongoing inflammation in the remaining tract near the origin of the fistula [2]. Inflammation in fistula tracts exhibits characteristics of chronic inflammation and proliferation of fibroblasts and epithelial cells [3]. Although living bacteria are infrequently found in fistula tracts, remnants of microorganism like peptidoglycan are found and might initiate chronic inflammation $[2,4,5]$. Peptidoglycan has potent pro-inflammatory properties by stimulating production of interleukin- $1 \beta$ and other inflammatory mediators. Recently, it was demonstrated that these cytokines are expressed in biopsies taken from chronic cryptoglandular fistulas $[2,5]$. These findings suggest that inflammatory mechanisms could play a role in the persistence of anal fistulas [3]. Therefore, it is theoretically possible to enhance the outcome of sphincter-preserving procedures by additional suppression of chronic inflammation.

Stromal vascular fraction (SVF), which is extracted from adipose tissue, is thought to have the potential to suppress chronic inflammation and promote tissue regeneration $[6,7]$. For many years, SVF was harvested by enzymatic digestion of lipoaspirate and subsequent centrifugation. Frequently, enzymatically digested SVF was expanded through in vitro culture to obtain adipose-derived stromal cells (ADSCs). This type of processing is time-consuming, expensive, and associated with the inherent risk of contamination [8]. Moreover, it only yields a single-cell suspension without other types of regulatory cells, extracellular matrix, or microvasculature [9]. Two recent developments have significantly changed both the processing and the use of SVF: first, the introduction of mechanical fractionation, which makes enzymatic digestion with collagenase, no longer required [9]; second, the finding that freshly isolated ADSCs show better differentiation potential as compared to culture-expanded ADSCs $[8,10]$. SVF, obtained by mechanical fractionation, consists of a heterogeneous cellular mixture including ASCs embedded in extracellular matrix and surrounded by an extensive network of small blood vessels. Platelet-rich plasma (PRP) is thought to reinforce the biological effect of SVF [11]. SVF enriched with PRP is also referred to as platelet-rich stroma (PRS), which may provide a unique tool to suppress chronic inflammation, and promote local tissue repair and even regeneration, as described by Stevens et al. [12].

The aim of this study was to assess the feasibility, safety, and efficacy of additional injection of autologous SVF enriched with PRP in TAFR of transsphincteric fistulas of cryptoglandular origin in tertiary referral patients.

\section{Materials and methods}

\section{Study design}

Between December 2017 and February 2020, consecutive patients with transsphincteric cryptoglandular fistula, who were scheduled for TAFR in a tertiary referral center, were enrolled in this prospective cohort study. Exclusion criteria were age under 18 years, associated pelvic abscess(es), rectovaginal fistula, the presence of a second internal opening above the dentate line, history of Crohn's disease, immune compromised status, hematological disorders, coagulation disorders, and/or any oncological event in the previous 5 years. All patients underwent standardized TAFR with additional injection of autologous SVF and PRP performed by three colorectal surgeons (W.R.S, O.R., and E.G.). In patients with associated abscess(es) detected on preoperative MR imaging, drainage was performed with seton or drain placement prior to the flap procedure.

Primary endpoint was primary fistula healing at clinical examination during follow-up, defined as complete closure of the external opening(s) without any fluid discharge from the fistula tract. Secondary endpoints were the occurrence of adverse events, obliteration of the fistula tract on magnetic resonance imaging (MRI), recurrence rate after initial fistula healing, and long-term follow-up. Postoperative outpatient visits at which physical examination was performed were scheduled at 6 weeks and 3, 6, and 12 months. However, if patients had no clinical complaints and were discharged before 12 months, telephone consultation was used to obtain 
their clinical status. In case of uncertainty, patients were seen at the outpatient clinic for physical examination. Prior to TAFR, the patient's medical history was recorded and physical examination was performed. Written informed consent was obtained from all subjects before entering the study, which was approved by the Medical Ethical Committee of the Erasmus Medical Center.

\section{MRI evaluation}

Prior to surgery, MRI was performed in all patients using a $1.5 \mathrm{~T}$. system with a four-channel phased array pelvic coil. Field of view consisted of the lower pelvis, perineum, and skin area with full display of the anus and lower mid rectum. The MRI protocol included T2-weighted (T2W) sequences in three planes: axial $\mathrm{T} 2 \mathrm{~W}$ with fat saturation, and sagittal and coronal T2W. Fistulas were identified based on hyperintense (white) signal. The course of the fistula tract, presence of secondary tracts, and associated abscess(es) were examined. When physical examination revealed closure of the external opening(s), MRI was repeated. Complete closure of the fistula tract(s) was defined as total absence of hyperintense signal. An experienced radiologist who was blinded for the clinical status (R.S.D.) interpreted the anonymized images of the pre- and postoperative MRI's.

\section{Operative techniques}

After induction of general endotracheal anesthesia, metronidazole $(500 \mathrm{mg})$ and cefuroxime $(2000 \mathrm{mg})$ were administered intravenously. The external opening(s) of the fistula was enlarged by coring out to the exterior of the external anal sphincter. If flap procedure was considered feasible, lipoaspiration for the harvesting of SVF was initiated [13]. A video of the procedure was previously published [13]. Due to the hypothetical risk of subcutaneous infection, liposuction was always performed prior to flap repair. A small paravertebral skin incision was made bilaterally approximately $5 \mathrm{~cm}$ cranial to the posterior superior iliac spine. Bilaterally, the subcutaneous adipose tissue was infiltrated with $20-40 \mathrm{ml} 0.9 \%$ saline solution, containing $20 \mathrm{mg} / \mathrm{ml}$ xylocaine and $5 \mu \mathrm{gram} / \mathrm{ml}$ adrenaline. Using vacuum, $15 \mathrm{ml}$ of lipoaspirate was harvested bilaterally, with a double syringe (Arthrex GMBH, München, Germany). Hereafter, each double syringe was put in a sterile centrifuge bucket. During the first centrifugation cycle ( $5 \mathrm{~min}, 2500 \mathrm{rpm}$ ), the TAFR procedure was continued. A Lone Star retractor (Lone Star Retractor System, Lone Star Medical Products ${ }^{\circledR}$, Inc., Houston, TX) was used to expose the internal opening, which was enlarged and the remaining crypt-bearing tissue was excised. A small rim of anoderm, distal of the internal opening, was excised to create a neo-dentate line. A flap comprising approximately one-third of the circumference, consisting of mucosa, submucosa, and some of the most superficial fibers of the internal anal sphincter, was raised from the level of the dentate line and mobilized over a distance of 4-6 $\mathrm{cm}$ proximally. Centrifugation of the lipoaspirate resulted in three separated fractions: oil, condensed fatty tissue, and aqueous fraction (Fig. 1A, I). The oil was transferred into the smaller inner syringe and discarded. The aqueous fraction was drained from the larger outer syringe. The remaining condensed fatty tissue was transferred to a $10 \mathrm{ml}$ syringe connected to another $10 \mathrm{ml}$ syringe by a $1.4 \mathrm{~mm}$ connector and fractionated by vigorously transferring the fatty tissue 30 times through this connector. After mechanical fractionation, the fatty tissue was centrifuged ( $5 \mathrm{~min}, 2500 \mathrm{rpm}$ ) (Fig. 1A, II). After the second centrifugation, the upper oily fraction was removed, resulting in $1 \mathrm{ml} \mathrm{SVF} \mathrm{[9].} \mathrm{A} \mathrm{venous}$ blood sample $(15 \mathrm{ml})$ was centrifuged $(4 \mathrm{~min}, 1500 \mathrm{rpm})$ after which 4-5 ml PRP was obtained (Fig. 1B). PRP, harvested this way, contains approximately $5 \times 10^{8}$ platelets $/ \mathrm{ml}$ [11]. SVF was combined with PRP, with a median volume of $7 \mathrm{cc}$, and injected with $1 \mathrm{cc}$ syringes in microblebs around and through the enlarged internal and external opening into all quadrants of the fistula wall. Hereafter, the internal opening was closed with absorbable sutures $2 / 0$ Vicryl (Ethicon, Inc., Somerville, NJ, USA). The flap was advanced and sutured to the neo-dentate line with absorbable sutures $2 / 0$ Monocryl (Ethicon, Inc., Somerville, NJ, USA). Standard local postoperative protocol included administration of postoperative antibiotics, discharge from the hospital after 3 days if possible, and no specific regulations for bed rest.

\section{Statistical analysis}

Continuous variables were recorded as means (standard deviation (SD)) for normally distributed data or medians (interquartile range [IQR]) for non-parametric data and categorical variables collated as frequencies and percentages. Statistical analysis was performed with IBM Statistical Packages for Social Sciences (SPSS) for Windows (IBM Corp., Armonk, NY, USA).

\section{Results}

\section{Demographics}

Forty-five consecutive patients (29 males [64.4\%]) with a median age of 44 years [range 36-53 years]) were enrolled. All patients completed 12 months of follow-up (median length of follow-up 1.7 years [IQR 1.3-2.0]). Median duration of symptoms prior to surgery was 2.5 years (range 0-16 years). Forty-three patients (95.6\%) previously underwent fistula surgery. The median number of prior procedures was 4 (IQR 2-6). In 22 patients (51.2\%) prior surgical 
Fig. 1 Mechanical fractionation procedure of SVF combined with PRP procedure. Lipoaspirate harvested by liposuction from subcutaneous fatty tissue is centrifuged ( $5 \mathrm{~min}$, $2500 \mathrm{rpm}$ ), resulting in $\pm 10 \mathrm{ml}$ condensed fatty tissue (A), mechanically fractionated and centrifuged again (5 min, $2500 \mathrm{rpm}$ ) to obtain $1 \mathrm{ml} \mathrm{SVF}$ (B). A venous blood sample $(15 \mathrm{ml})$ is centrifuged $(4 \mathrm{~min}$, $1500 \mathrm{rpm})$ after which $4-5 \mathrm{ml}$ PRP was obtained (C). $S V F$ stromal vascular fraction; $P R P$ platelet-rich plasma
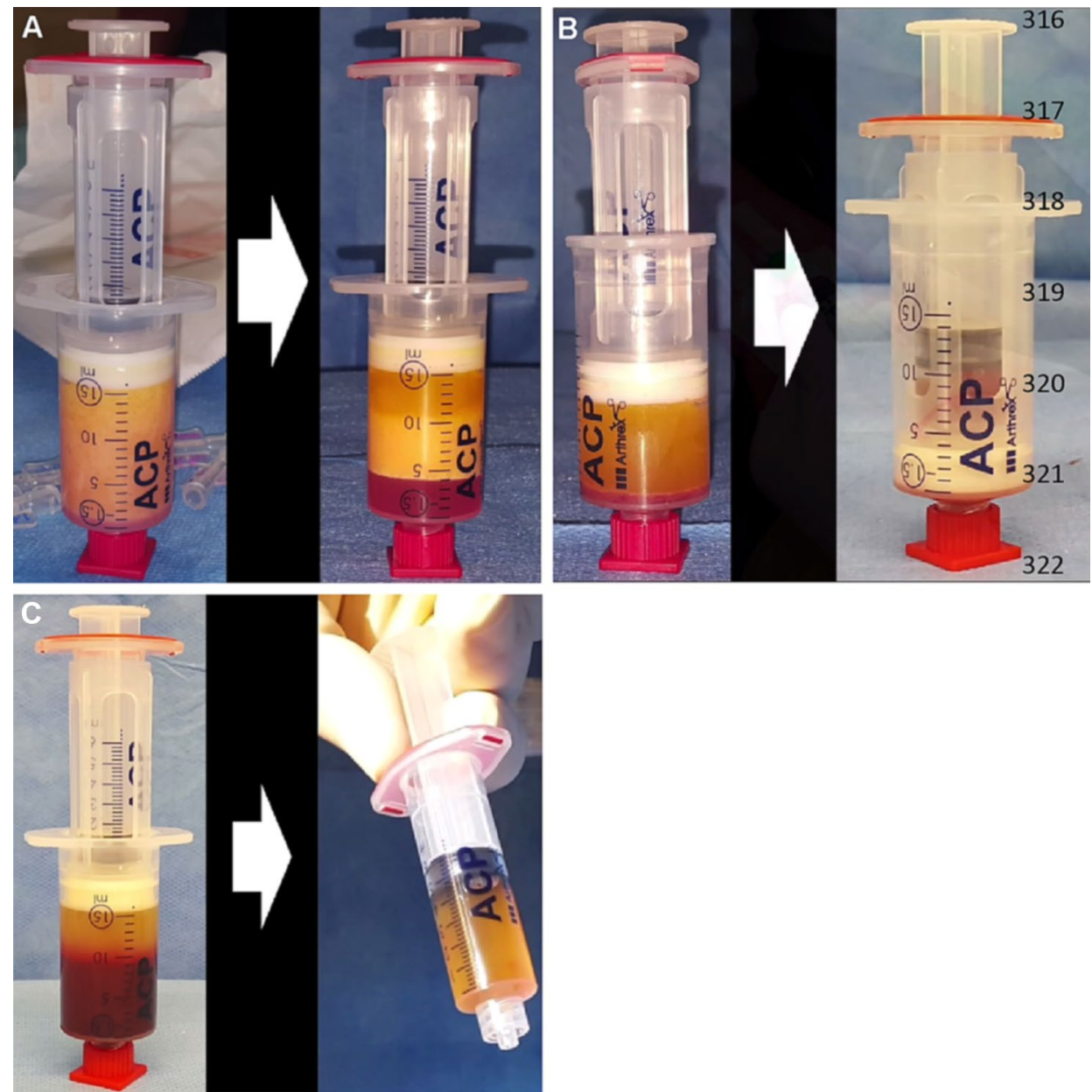

procedures concerned attempts at fistula closure (Table 1). At time of surgery, 3 patients were diverted. None of the patients had any synchronous perianal pathology.

\section{Surgical procedure}

The mean operating time was $82 \mathrm{~min}( \pm \mathrm{SD} 22)$. The median yield of SVF and PRP was $7 \mathrm{ml}$ (range 3-12 ml). The creation of the flap was uneventful except for one patient in whom a longitudinal tear occurred, which could be restored. The median length of hospital stay was 3 days (range 2-4 days).

\section{Outcomes}

\section{Primary endpoint}

Primary fistula healing was observed in $38 / 45$ patients $(84 \%)$. One of these patients encountered recurrence, resulting in a long-term success rate of $82 \%$ (37/45). Six patients in whom the fistula persisted or recurred underwent further treatment aimed at fistula closure. Two patients were successfully treated with subsequent laser coagulation. Four patients underwent a second TAFR with injection of SVF enriched with PRP, which was successful in one patient. The three patients with persisting fistula refrained from further treatment.

\section{Secondary endpoints}

The preparation of SVF and PRP was carried out without problems. No adverse events were encountered at the lipoharvesting sites. The postoperative course was uneventful, except in three cases; venous thromboembolism in one patient and bleeding under the flap, necessitating re-intervention, in two patients. Following fistula healing, MRI evaluation was performed in all patients, except for one patient who suffered from claustrophobia. The median length of time between operation and postoperative MRI was 6.6 (IQR 4.7-7.5) months. MRI revealed complete closure in 33 out of 37 patients with clinical healing (89.2\%) (Fig. 2). In two patients, the fistula tract was almost completely filled with fibrotic tissue, except for a minor part (Fig. 3). In the other two patients, the fistula tract was partly obliterated by scar 
Table 1 Baseline characteristics of patient with cryptoglandular fistulas who underwent SVF with PRP

\begin{tabular}{|c|c|}
\hline Variables & $N=45$ \\
\hline \multicolumn{2}{|l|}{ Age (years) } \\
\hline Median (IQR) & $44.0(36.2-53.3)$ \\
\hline \multicolumn{2}{|l|}{ Sex } \\
\hline Male $(\%)$ & $29(64.4)$ \\
\hline \multicolumn{2}{|l|}{ Follow-up (years) } \\
\hline Median (IQR) & $1.7(1.3-2.0)$ \\
\hline \multicolumn{2}{|l|}{ Duration of symptoms prior to surgery (years) } \\
\hline Median (IQR) & $2.5(1.1-5.5)$ \\
\hline Range & $0-15.8$ \\
\hline \multicolumn{2}{|l|}{ Deviating stoma at time of surgery } \\
\hline Number of patients (\%) & $3(6.7)$ \\
\hline Complex fistula (high transsphincteric and/or multiple side tracts) & $39(86.7)$ \\
\hline \multicolumn{2}{|l|}{ Fistula classification } \\
\hline High transsphincteric $(\%)$ & $37(82.2)$ \\
\hline Low transsphincteric $(\%)$ & $8(17.8)$ \\
\hline \multicolumn{2}{|l|}{ Fistula extension } \\
\hline No side tracts $(\%)$ & $21(46.7)$ \\
\hline 1 side tract & $11(24.4)$ \\
\hline$\geq 2$ side tracts & $13(28.9)$ \\
\hline \multicolumn{2}{|l|}{ Prior fistula surgery } \\
\hline Number of patients (\%) & $43(95.6)$ \\
\hline \multicolumn{2}{|l|}{ Total number of fistula procedures prior to PRS surgery } \\
\hline Median (IQR) & $4(2-6)$ \\
\hline \multicolumn{2}{|l|}{ Prior fistula procedures aimed at fistula repair } \\
\hline TAFR and/or LIFT (\%) & $22(48.9)$ \\
\hline Fistulotomy and/or fistulectomy (\%) & $4(9)$ \\
\hline \multicolumn{2}{|l|}{ Previous abscess drainage } \\
\hline Abscess drainage without drain or seton placement & $28(62.2)$ \\
\hline Abscess drainage with drain or seton placement & $14(31.1)$ \\
\hline Seton placement alone & $28(62.2)$ \\
\hline
\end{tabular}

$S V F$ stromal vascular fraction, $P R P$ platelet-rich plasma, $P R S$ platelet-rich stroma, TAFR transanal advancement flap repair, LIFT ligation of intersphincteric fistula tract tissue. To date, these four patients have not shown any signs of recurrence. Of the three patients who were diverted at time of surgery, one patient underwent restoration of bowel continuity following fistula healing. To date, the other two patients have not undergone stoma reversal despite complete fistula closure. In the 42 patients with intestinal continuity at time of surgery, primary fistula healing was observed in 35 patients $(84 \%)$.

\section{Discussion}

The present study showed that additional treatment with autologous adipose-derived SVF enriched with PRP is feasible, safe, and seems to result in a better outcome of flap repair in patients with transsphincteric, cryptoglandular fistula. The median duration of follow-up was 1.7 years, which is adequate to determine the overall healing rate [14]. Our study also revealed that MRI is a useful tool to confirm fistula healing in cryptoglandular disease.

A recent systematic review and meta-analysis comprising 721 patients revealed a weighted overall TAFR success rate of $74.6 \%$ [15]. However, the reported healing rates ranged widely from 33 to $95 \%$, probably due to major heterogeneity with respect to the number of patients with a complex or recurrent fistula. Most reviewed series were small, with a median number of patients of only 35 [15]. Our group reported the largest series in this review in 2014, which comprised 252 patients with a healing rate of only $59 \%$ [1]. The first study conducted by our group in the early $90 \mathrm{~s}$ showed fistula healing after flap repair in $75 \%$ of the patients [16], suggesting that healing rates have dropped in the past decades probably inherent to increasing numbers of tertiary referrals with complex fistula. Thus, a weighted 
Fig. 2 Preoperative and postoperative MRI in 2 patients with fistula healing, showing: A preoperative MRI (sagittal view) of a transsphincteric fistula with horseshoe extension complete obliteration of the fistula tract (patient 1); $\mathbf{B}$ postoperative MRI (sagittal view) at 6 months shows complete obliteration of the fistula tract with fibrotic tissue (patient 1); $\mathbf{C}$ preoperative MRI (coronal view) of a transsphincteric fistula (patient 2); D postoperative MRI (coronal view) at 6 months shows complete obliteration of the fistula tract with fibrotic tissue (patient 2). MRI magnetic resonance imaging


Fig. 3 Preoperative and postoperative MRI in a patient with fistula healing, showing incomplete obliteration of the fistula tract: A preoperative MRI (transverse view) of a transsphincteric fistula, showing parts of the fistula tract at both lateral side and in the posterior midline; B postoperative MRI (transverse view) at 6 months shows incomplete obliteration of the fistula tract with remains of the fistula in the intersphincteric plane at the right and left sides. MRI magnetic resonance imaging overall success rate of more than $74 \%$ does not reflect daily practice of tertiary referral centers.

A high failure rate after conventional TAFR without additional treatment is probably due to ongoing chronic inflammation in the residual fistula tissue [4]. This notion is supported by the fact that fistulectomy, the only intervention resulting in complete excision of all inflamed tissue, obtains much higher healing rates then can be obtained with any sphincter-preserving procedure. Furthermore, our group observed that in almost all patients who failed TAFR, the sutured flap was healed completely except at the original internal opening. This indicates that ischemia and flap retraction play a minor role in failure [14]. It is conceivable that the outcome of TAFR may be enhanced by suppressing chronic inflammation while simultaneously promoting wound healing. This prompted us to select SVF enriched with PRP to achieve this goal. 
Table 2 Autologous adipose-derived stromal/stem cells (ADSCs) in cryptoglandular anal fistulas

\begin{tabular}{|c|c|c|c|c|c|c|}
\hline Author & Year & $\begin{array}{l}\text { Num- } \\
\text { ber of } \\
\text { patients }\end{array}$ & $\begin{array}{l}\text { Processing } \\
\text { ADSCs }\end{array}$ & Surgical procedure & $\begin{array}{l}\text { Follow- } \\
\text { up } \\
\text { (months) }\end{array}$ & Healing $(\%)$ \\
\hline Herreros [36] (Phase III trial) & 2012 & 64 & $\begin{array}{l}\text { Enzymatic isolation + culture expan- } \\
\text { sion }\end{array}$ & Simple closure & 12 & 57 \\
\hline Garcia, Herreros [37] (Phase II trial) & 2009 & 60 & $\begin{array}{l}\text { Enzymatic isolation + culture expan- } \\
\text { sion }\end{array}$ & Simple closure + glue & 12 & 52 \\
\hline Borowski [39] & 2015 & 7 & Enzymatic isolation SVF alone & Simple closure & 46 & 57 \\
\hline Choi [38] & 2017 & 13 & $\begin{array}{l}\text { Enzymatic isolation + culture expan- } \\
\text { sion }\end{array}$ & Simple closure & 2 & 69 \\
\hline Naldini [40] & 2018 & 19 & Mechanical fractionation SVF alone & Two-layered closure & 12 & 74 \\
\hline Present study & 2020 & 27 & Mechanical fractionation SVF+PRP & Flap repair & 8 & 85 \\
\hline
\end{tabular}

$S V F$ stromal vascular fraction, $P R P$ platelet-rich plasma

The use of mesenchymal stromal cells (MSCs) for regenerative medicine has been advocated since their discovery in the early 70 s, due to their anti-inflammatory properties and ability to differentiate into multiple lineages $[17,18]$. The easy accessibility, high vascularization, and relative high yield of ADSCs make adipose tissue a great source. While the use of isolated ADSCs has been shown to be efficacious in several wound healing models $[19,20]$, it often requires in vitro expansion of ADSCs. This affects their biological activity, is expensive, and may potentially introduce contamination $[8,10,21]$. Mechanically fractionated SVF may perform equally well or even better than isolated and culture-expanded ADSCs [22]. Cells present in SVF include macrophages, stromal cells, and endothelial cells, which play a pivotal role in tissue repair [23, 24]. Like ASCs, SVF has immunomodulatory properties and contributes to the downregulation of the pro-inflammatory cytokines IL-1B and IL6 [6, 25]. It also has distinct angiogenetic properties, which are more effective than those of ADSCs alone [20]. These properties may be related to the presence of intact microvasculature and extracellular matrix within SVF, as prevascularisation can enhance neovascularization [26, 27]. Furthermore, SVF improves and stabilizes the microvasculature assembled by endothelial cells [7, 28].

PRP is a rich source of growth factors and enhances proliferation, differentiation, and neovascularization induced by stromal cells [29-31]. In addition, the fibrin network of PRP has the potential to serve as a scaffold, holding cells, and platelets in a three-dimensional arrangement. This interaction may enhance and prolong survival of stromal cells at the administration site [32]. In porcine and murine models, stromal cells enriched with PRP resulted in better revascularization and wound healing as compared to stromal cells alone $[33,34]$ This synergistic interaction prompted our decision to use SVF enriched with PRP. It should be noted that the composition of autologous preparations of SVF and PRP might differ from donor to donor, which in turn potentially affects healing rates [35].

The role of cultured stem cells in the treatment of anal fistulas, especially in Crohn's disease, has gained increasing attention during the last decade (Table 2). Herreros et al. randomly assigned patients with transsphincteric, cryptoglandular fistula to receive 20 million cultured ADSCs $(n=64), 20$ million ADSCs plus fibrin glue $(n=60)$, or fibrin glue alone $(n=59)$ after simple closure of the internal opening. At 1 year, observed healing rates were $57 \%$, $52 \%$, and $37 \%$, respectively $[36,37]$. Choi et al., also using ADSCs, observed a healing rate of $69 \%$ at 8 weeks [38]. The use of autologous SVF in the treatment of cryptoglandular fistulas was first reported in 2015. After enzymatic digestion of the lipoaspirate within a fully automated Celution 800/CRS system, it was washed and centrifuged to obtain $\mathrm{SVF}$, which was injected into and around the fistula tract upon simple closure of the internal opening. At 46 months, this procedure was found to be successful in 4/7 patients [39]. Naldini and co-workers obtained SVF by mechanical fractionation of fatty tissue, similar to our fractionation technique, and showed a healing rate of $74 \%$ of 19 patients after 12 months of SVF injection into the wall of the fistula tract, followed by two-layered closure of the internal opening [40]. As primary treatment, the healing rate was $83 \%$, whereas the success rate was $57 \%$ in patients in whom previous procedures had failed [40]. The results obtained from these studies suggest that closure of the internal opening with additional injection of stem or stromal cells results in a better outcome than closure of the internal opening alone. In 2018, Wainstein et al. used enzymatically isolated and culture-expanded ADSCs combined with PRP as an adjunct to flap repair in 9 patients with 11 fistulas due to Crohn's disease. According to the authors, 10 fistulas healed after a median follow-up of 31 months [41]. This striking result indicates that additional injection of stromal cells combined with platelets may also 
be beneficial for patients with Crohn's disease eligible for flap repair.

The main limitations of our study were the small sample size and lack of a control group. A randomized study is needed to compare the effect of SVF enriched with PRP treatment in other perianal pathologies, including Crohn's disease, and determine whether injection of SVF enriched with PRP without flap repair is also feasible. The strength of our study lies in the new and simple perioperative technique to harvest SVF by mechanical fractionation of adipose tissue. This method was found to be quick, inexpensive, and independent of laboratory facilities, providing immediate preparation of ADSCs. Another strong feature of this study is our choice to combine SVF with PRP, based on their synergistic interaction. To the best of our knowledge, the present study is the first study that evaluates the effect of SVF enriched with PRP as an adjunct to TAFR for cryptoglandular fistulas.

\section{Conclusions}

The long-term success rate of $82 \%$ is higher than in other studies, indicating that additional treatment with SVF enriched with PRP is a promising tool to improve the outcome of TAFR in patients with a transsphincteric, cryptoglandular fistula in a tertiary referral center. Further research is needed to define the appropriate ratio between, and optimal amount of, SVF and PRP in correlation with clinical outcome.

\section{Funding None.}

Availability of data and materials Equipment supplied by Arthrex GMBH, München, Germany.

\section{Declarations}

Conflict of interest The authors declare that they have no conflict of interest.

Ethical approval and Informed consent Written informed consent was obtained from all subjects before entering the study, which was approved by the Medical Ethical Committee of the Erasmus Medical Center.

Open Access This article is licensed under a Creative Commons Attribution 4.0 International License, which permits use, sharing, adaptation, distribution and reproduction in any medium or format, as long as you give appropriate credit to the original author(s) and the source, provide a link to the Creative Commons licence, and indicate if changes were made. The images or other third party material in this article are included in the article's Creative Commons licence, unless indicated otherwise in a credit line to the material. If material is not included in the article's Creative Commons licence and your intended use is not permitted by statutory regulation or exceeds the permitted use, you will need to obtain permission directly from the copyright holder. To view a copy of this licence, visit http://creativecommons.org/licenses/by/4.0/.

\section{References}

1. van Onkelen RS et al (2014) Predictors of outcome after transanal advancement flap repair for high transsphincteric fistulas. Dis Colon Rectum 57(8):1007-1011

2. van Onkelen RS et al (2013) Assessment of microbiota and peptidoglycan in perianal fistulas. Diagn Microbiol Infect Dis 75(1):50-54

3. Ratto C et al (2016) Immunopathological characterization of cryptoglandular anal fistula: a pilot study investigating its pathogenesis. Colorectal Dis 18(12):O436-O444

4. Sugrue J et al (2017) Pathogenesis and persistence of cryptoglandular anal fistula: a systematic review. Tech Coloproctol 21(6):425-432

5. van Onkelen RS et al (2016) Pro-inflammatory cytokines in cryptoglandular anal fistulas. Tech Coloproctol 20(9):619-625

6. Zhu M et al (2019) Anti-inflammatory effect of stromal vascular fraction cells in fat transplantation. Exp Ther Med 17(2):1435-1439

7. van Dongen JA et al (2018) Augmentation of Dermal Wound Healing by Adipose Tissue-Derived Stromal Cells (ASC). Bioengineering 5(4):91

8. Brooks AES et al (2019) Ex Vivo Human Adipose Tissue Derived Mesenchymal Stromal Cells (ASC) Are a Heterogeneous Population That Demonstrate Rapid Culture-Induced Changes. Front Pharmacol 10:1695

9. van Dongen JA et al (2016) The fractionation of adipose tissue procedure to obtain stromal vascular fractions for regenerative purposes. Wound Repair Regen 24(6):994-1003

10. Wall ME, Bernacki SH, Loboa EG (2007) Effects of serial passaging on the adipogenic and osteogenic differentiation potential of adipose-derived human mesenchymal stem cells. Tissue Eng 13(6):1291-1298

11. Oudelaar BW et al (2019) Concentrations of blood components in commercial platelet-rich plasma separation systems: a review of the literature. Am J Sports Med 47(2):479-487

12. Stevens HP, Donners S, de Bruijn J (2018) Introducing PlateletRich Stroma: Platelet-Rich Plasma (PRP) and Stromal Vascular Fraction (SVF) Combined for the Treatment of Androgenetic Alopecia. Aesthet Surg J 38(8):811-822

13. Deijl W et al (2020) Autologous platelet-rich stroma in complex perianal fistulas. Dis Colon Rectum 63(6):860-861

14. Mitalas LE et al (2009) Required length of follow-up after transanal advancement flap repair of high transsphincteric fistulas. Colorectal Dis 11(7):726-728

15. Stellingwerf ME et al (2019) Systematic review and meta-analysis of endorectal advancement flap and ligation of the intersphincteric fistula tract for cryptoglandular and Crohn's high perianal fistulas. BJS Open 3(3):231-241

16. Schouten WR, Zimmerman DD, Briel JW (1999) Transanal advancement flap repair of transsphincteric fistulas. Dis Colon Rectum 42(11):1419-1422 (discussion 1422-1423)

17. Maxson $\mathrm{S}$ et al (2012) Concise review: role of mesenchymal stem cells in wound repair. Stem Cells Transl Med 1(2):142-149

18. Shyam $\mathrm{H}$ et al (2017) Mesenchymal stem cells in regenerative medicine: a new paradigm for degenerative bone diseases. Regen Med 12(2):111-114 
19. Bi $\mathrm{H}$ et al (2019) Stromal vascular fraction promotes migration of fibroblasts and angiogenesis through regulation of extracellular matrix in the skin wound healing process. Stem Cell Res Ther 10(1):302

20. Bora P, Majumdar AS (2017) Adipose tissue-derived stromal vascular fraction in regenerative medicine: a brief review on biology and translation. Stem Cell Res Ther 8(1):145

21. Kozlowska U et al (2019) Similarities and differences between mesenchymal stem/progenitor cells derived from various human tissues. World J Stem Cells 11(6):347-374

22. Andia I, Maffulli N, Burgos-Alonso N (2019) Stromal vascular fraction technologies and clinical applications. Expert Opin Biol Ther 19(12):1289-1305

23. Spees JL, Lee RH, Gregory CA (2016) Mechanisms of mesenchy$\mathrm{mal}$ stem/stromal cell function. Stem Cell Res Ther 7(1):125

24. Sun Y et al (2019) Significance of Cellular Cross-Talk in Stromal Vascular Fraction of Adipose Tissue in Neovascularization. Arterioscler Thromb Vasc Biol 39(6):1034-1044

25. Dong $\mathrm{Z}$ et al (2013) The survival condition and immunoregulatory function of adipose stromal vascular fraction (SVF) in the early stage of nonvascularized adipose transplantation. PLOS ONE 8(11):e80364

26. Muller S et al (2019) Human adipose stromal-vascular fraction self-organizes to form vascularized adipose tissue in $3 \mathrm{D}$ cultures. Sci Rep 9(1):7250

27. Ramakrishnan VM, Boyd NL (2018) The Adipose Stromal Vascular Fraction as a Complex Cellular Source for Tissue Engineering Applications. Tissue Eng Part B Rev 24(4):289-299

28. Ebrahimian TG et al (2009) Cell therapy based on adipose tissuederived stromal cells promotes physiological and pathological wound healing. Arterioscler Thromb Vasc Biol 29(4):503-510

29. Lai $\mathrm{F}$ et al (2018) Platelet-rich plasma enhances the proliferation of human adipose stem cells through multiple signaling pathways. Stem Cell Res Ther 9(1):107

30. Lucarelli E et al (2003) Platelet-derived growth factors enhance proliferation of human stromal stem cells. Biomaterials 24(18):3095-3100

31. Willemsen JC et al (2016) Platelet-rich plasma influences expansion and paracrine function of adipose-derived stromal cells in a dose-dependent fashion. Plast Reconstr Surg 137(3):554e-565e
32. Tobita M, Tajima S, Mizuno H (2015) Adipose tissue-derived mesenchymal stem cells and platelet-rich plasma: stem cell transplantation methods that enhance stemness. Stem Cell Res Ther $6: 215$

33. Bhang SH et al (2013) Platelet-rich plasma enhances the dermal regeneration efficacy of human adipose-derived stromal cells administered to skin wounds. Cell Transplant 22(3):437-445

34. Blanton MW et al (2009) Adipose stromal cells and platelet-rich plasma therapies synergistically increase revascularization during wound healing. Plast Reconstr Surg 123(2 Suppl):56S-64S

35. van Dongen JA, Harmsen MC, Stevens HP (2019) Isolation of Stromal Vascular Fraction by fractionation of adipose tissue. Methods Mol Biol 1993:91-103

36. Herreros MD et al (2012) Autologous expanded adipose-derived stem cells for the treatment of complex cryptoglandular perianal fistulas: a phase III randomized clinical trial (FATT 1: fistula advanced therapy trial 1) and long-term evaluation. Dis Colon Rectum 55(7):762-772

37. Garcia-Olmo D et al (2009) Expanded adipose-derived stem cells for the treatment of complex perianal fistula: a phase II clinical trial. Dis Colon Rectum 52(1):79-86

38. Choi $\mathrm{S}$ et al (2017) Autologous adipose tissue-derived stem cells for the treatment of complex perianal fistulas not associated with Crohn's disease: a phase II clinical trial for safety and efficacy. Tech Coloproctol 21(5):345-353

39. Borowski DW et al (2015) Adipose tissue-derived regenerative cell-enhanced Lipofilling for treatment of Cryptoglandular Fistulae-in-Ano: the ALFA technique. Surg Innov 22(6):593-600

40. Naldini $G$ et al (2018) Micro-fragmented adipose tissue injection for the treatment of complex anal fistula: a pilot study accessing safety and feasibility. Tech Coloproctol 22(2):107-113

41. Wainstein C et al (2018) Stem cell therapy in refractory perineal Crohn's Disease: long-term follow-up. Colorectal Dis. https://doi. org/10.1111/codi.14002

Publisher's Note Springer Nature remains neutral with regard to jurisdictional claims in published maps and institutional affiliations.

\section{Authors and Affiliations}

\section{W. R. Schouten ${ }^{1}$ - J. H. C. Arkenbosch ${ }^{2}$ (1) - C. J. van der Woude ${ }^{2}$ - A. C. de Vries ${ }^{2}$ - H. P. Stevens ${ }^{3}$ - G. M. Fuhler ${ }^{2}$. R. S. Dwarkasing ${ }^{4}$ O. van Ruler ${ }^{1,2}$. E. J. R. de Graaf ${ }^{1}$}

W. R. Schouten

w.r.schouten@gmail.com

1 Department of Surgery, IJsselland Hospital, Prins Constantijnweg 2, 2906 ZC Capelle aan den IJssel, The Netherlands

2 Department of Gastroenterology and Hepatology, Erasmus University Medical Center, Rotterdam, The Netherlands
3 Department of Plastic Surgery, Velthuis Clinics / PRSclinics, Rotterdam, The Netherlands

4 Department of Radiology, Erasmus University Medical Center, Rotterdam, The Netherlands 